\title{
Exceptionally broad bulk metallic glass formation in the $\mathrm{Mg}-\mathrm{Cu}-\mathrm{Yb}$ system
}

\author{
Karl F. Shamlaye ${ }^{* 1}$, Kevin J. Laws ${ }^{1,2}$, Jörg F. Löffler ${ }^{1}$ \\ ${ }^{1}$ Laboratory of Metal Physics and Technology, Department of Materials, ETH Zurich, 8093 Zurich, Switzerland \\ ${ }^{2}$ School of Materials Science and Engineering, UNSW Australia, Sydney, NSW 2052, Australia
}

Keywords: Bulk metallic glasses; Glass-forming ability; Predictive structural model

\section{Abstract}

This study presents an extensive series of novel bulk metallic glasses (BMGs) which broadly span all three corners of the $\mathrm{Mg}-\mathrm{Cu}-\mathrm{Yb}$ ternary system. Over 30 alloys were synthesised within a wide composition range from (at.\%): Mg: $13-55, \mathrm{Cu}: 17.5-$ 45.5, and $\mathrm{Yb}: 9-70$. In terms of composition, this ternary system is considered to be one of the broadest for bulk glass formation known - this probably due to the three elements' thermodynamic compatibility and unique combinations of atomic radii, which generate specific, favoured structural topologies. The investigation reports the design method, critical casting size, thermophysical characteristics and mechanical properties of these new BMGs.

\section{Introduction}

While the possibility of metallic glass formation from the melt has been known to science for over 50 years [1], in terms of amorphous alloy discovery and development many potential glass-forming systems remain uncharted. With respect to the periodic table, vast expanses of ternary, quaternary and extended multicomponent alloy composition space have yet to be explored [2]. This is because fast, efficient and accurate means of probing composition space are beyond the means of basic alloy production techniques. Despite this, amorphous alloy structural modelling and glass-formation prediction techniques have advanced substantially in the last 
decade, generating many methods ranging from first principles/ab initio [3-6, thermodynamic $[7,8]$ and topological [3-11] models which prove useful to varying degrees.

With the discovery of bulk glass formation in the $\mathrm{Mg}-\mathrm{Cu}-\mathrm{Y}$ ternary system in 1991, [12] numerous Mg-based ternary glass-forming systems which also contain $\mathrm{Cu}$ have been discovered. These have mostly been Mg-rich, based on the $\mathrm{Mg}-\mathrm{Cu}-\mathrm{RE}$ systems [13-17] ( where RE = Rare Earth = Y, Gd, Nd, Dy, Tb, Er etc. $)$ or the more recent bulk-glass-forming $\mathrm{Mg}-\mathrm{Cu}-\mathrm{Ca}$ ternary system [18]. Essentially, the driving force behind the production of these high Mg or -Ca containing alloys has been to develop a new category of light-metal alloys with high specific strengths in addition to other useful engineering properties $[19,20]$. Typically these ternary compositions are extended to quaternary or quinary alloys in a piecewise manner to enhance glassforming ability (GFA) and/or other specific properties. For example, 8.5 at.\% Ag can be substituted for $\mathrm{Cu}$ in the $\mathrm{Mg}_{58.5} \mathrm{Cu}_{30.5} \mathrm{Gd}_{11}$ alloy (casting thickness, $D_{\mathrm{c}}=9 \mathrm{~mm}$ ) to obtain a $27 \mathrm{~mm}$ bulk glass [21].

However, in terms of amorphous alloy discovery related to this work, Wang and co-workers [22] synthesised amorphous alloys based on the popular $\mathrm{Mg}_{65} \mathrm{Cu}_{25} \mathrm{RE}_{10}$ formula, with nearly all the Lanthanide series elements, including $\mathrm{Yb}$. In spite of successes with the other RE elements, the XRD trace of a $1 \mathrm{~mm}$ diameter $\mathrm{Mg}_{65} \mathrm{Cu}_{25} \mathrm{Yb}_{10}$ rod specimen showed numerous crystalline peaks. Tsarkov and coworkers [23] also recently investigated the effect of glass forming ability (GFA) by adding $\mathrm{Ag}$ and $\mathrm{Ca}$ to $\mathrm{a} \mathrm{Mg}_{65} \mathrm{Cu}_{25} \mathrm{Yb}_{10}$ base alloy, which in neither case produced a bulk glass. In light of this it would seem that $\mathrm{Yb}$ is not suitable for glass formation within this specific Mg-rich composition space, or at least that it behaves very differently to other Lanthanide elements at this composition. 
Cu-based BMGs have generated considerable interest due to their relatively low material cost, notably high compressive fracture strengths (1900-2500 MPa $[24,25]$ ) and large plastic strain before fracture (in some cases up to 18\%) [26]. However, most have been based on alloy systems that contain at least one group IV transition metal $(\mathrm{Zr}, \mathrm{Hf}$ and $\mathrm{Ti})$ as a major alloying element, making $\mathrm{Cu}$-based BMGs which do not contain these elements somewhat unique. As an alternative numerous Cu-base BMGs have been recently discovered in the Cu-Mg-Ca system [27].

To date the only Yb-based BMGs were found by Wang et al. [28] in the Yb$\mathrm{Zn}-\mathrm{Mg}$ system, exhibiting casting diameters of up to $2 \mathrm{~mm}$, which upon minor Cuaddition (5 at. \%) increases to a maximum of $4 \mathrm{~mm}$. This suggests a possible window of opportunity for favourable glass formation between $\mathrm{Yb}, \mathrm{Mg}$ and $\mathrm{Cu}$.

In this work we apply a predictive topological model $[10,29]$ to establish regions of possible glass formation in the $\mathrm{Mg}-\mathrm{Cu}-\mathrm{Yb}$ system. Implementing this method has previously proved useful for discovering numerous novel bulk metallic glasses in a wide range of ternary systems [18,27,29-32]. It is of fundamental scientific interest to ascertain the existence of other simple ternary BMG-forming systems (in particular Mg-, $\mathrm{Cu}$ - and $\mathrm{Yb}$-based) and further develop the means by which new systems might be predicted to aid new rapid amorphous alloy development strategies.

\section{Alloy design concept}

It is mentioned above that $\mathrm{Yb}$ appears to behave differently from other lanthanide series metals with respect to glass formation. On careful inspection it is found that $\mathrm{Yb}$ stands out among the lanthanide metals in that it can exhibit a stable 2+ oxidation state [33] (with a full $f$-shell of electrons), making it electronically analogous to $\mathrm{Mg}$ or

Ca in their outer electron shell configurations. Conceptually this electronic 
configuration further distinguishes $\mathrm{Yb}$ from other $\mathrm{RE}$ elements in that its atomic radius is essentially increased from the typical $\sim 180-185 \mathrm{pm}$ in the $3+$ state to $\sim 194 \mathrm{pm}$ when adopting the $2+$ state [33]. Hence $\mathrm{Yb}$ can be an ideal electronic and topological substitution for $\mathrm{Ca}$ (radius $\sim 197 \mathrm{pm}$ ), given that the two elements have very similar atomic radii. In addition to the atomic size mismatch between $\mathrm{Yb}, \mathrm{Mg}$ and $\mathrm{Cu}$, the elements also have negative heats of mixing with one another $\left(\mathrm{Mg}-\mathrm{Cu}:-3 \mathrm{KJmol}^{-1}\right.$; $\mathrm{Cu}-\mathrm{Yb}:-12 \mathrm{KJmol}^{-1}$, and $\mathrm{Mg}-\mathrm{Yb}:-6 \mathrm{KJmol}^{-1}$ ) [22], which further encourages the potential for glass formation. An ideal 'sister' or 'mirror' system for comparison is the Mg-Cu-Ca ternary, whereby numerous BMGs have been discovered in the Cabased region by Senkov et al. [34] and Amiya et al. [35], and by Laws et al. in the Mg-rich [18] and the Cu-based region [29]. Thus a topologically similar Mg-Cu-Yb system is also expected to yield numerous glasses over a broad compositional range.

It is well known that diffusion kinetics play a key role in the nucleation of crystallites or the retention of the amorphous state upon cooling/relaxation. It is also known that a tightly or efficiently-packed liquid structure significantly impedes atomic diffusion upon cooling from the melt (extrinsically viewed as increased melt viscosity), hindering nucleation kinetics - in turn leading to a lower critical cooling rate and greater glass-forming ability $[9,29]$. The topological model used in this work to guide us in determining glass-forming composition ranges takes into account the efficiency of packing atoms (considered here to be hard spheres) that constitute the composition of the alloy around each individual atom center. That is, in a perfectly efficient packing composition every atom in a given atom's first coordination shell is touching that central atom and its nearest neighbours - and that 'cluster' of atoms is equivalent to the composition of the alloy. Atomic radii of $\mathrm{Cu}=126 \mathrm{pm}, \mathrm{Mg}=160 \mathrm{pm}$ and $\mathrm{Yb}=194 \mathrm{pm}$ were used for this calculation (an in depth description on carrying 
out these calculations can be found in refs [10] and [29]). When each individual atomic centre can be simultaneously efficiently packed at a given alloy composition the 'global' structure of the alloy is considered efficiently packed, and hence most likely to exhibit enhanced glass-forming ability [10]. Mathematically speaking, a larger difference in atomic radii in a ternary system gives a larger range of possible coordination numbers as composition changes throughout the system [29,32]. This means that with a change in alloy composition, atoms in the first coordination shell of a cluster are substituted - the greater the difference in atomic size of constituents, the more significant the progressive change in coordination number. Hence with approximately $20 \%$ difference in atomic size between $\mathrm{Cu}-\mathrm{Mg}$ and $\mathrm{Mg}-\mathrm{Yb}$ a broad glass-forming range would be expected, similar to that of the $\mathrm{Mg}-\mathrm{Cu}-\mathrm{Ca}$ system $[18,29,34]$.

The 3 heavy black dashed lines in Figure 1(a) indicate the ideal compositions for perfect packing for all three atomic centres (determined by Laws et al. in Table S1 of reference [10]), applied to the atomic radius ratios of the $\mathrm{Mg}-\mathrm{Cu}-\mathrm{Yb}$ system; these have been shown to be preferred coordination combinations for glass formation $[10,36,37]$. The coordination number of each element along these perfect packing lines is indicated in $<$ parentheses $>$. For example, $\langle 9><12><15>$ represents a coordination number of 9 around the smallest atom, $\mathrm{Cu} ; 12$ around the mid-sized atom, Mg; and 15 around the largest atom, Yb. The yellow-shaded region highlights a $\pm 3 \%$ deviation from the ideal radius ratio required for perfect packing efficiency, which is considered to be a reasonable fluctuation for bulk glass formation or the possible error in using fixed radii for atoms in a hard-sphere model [10]. These composition regions are also truncated where a complete $\mathrm{Cu}, \mathrm{Mg}$ or $\mathrm{Yb}$ atomic centred cluster cannot be constructed, e.g. a Yb-centred cluster coordinated by 17 atoms cannot be a structural representative of the alloy composition when the $\mathrm{Yb}$ 
content is less than $1 /(17+1)$ or 5.55 at. $\%$. [10]. From within these calculated regions potential glass-forming compositions from the $\mathrm{Mg}-, \mathrm{Cu}$-, and $\mathrm{Yb}$-based regions of the $\mathrm{Mg}-\mathrm{Cu}-\mathrm{Yb}$ ternary system were synthesised and analysed.

\section{Experimental procedures}

The predicted glass-forming compositions were prepared and tested for GFA.

Nominal alloy compositions (shown in Tables 1, 2, and 3) were prepared using highpurity metals; Mg (99.99 wt.\%), Cu (99.99 wt.\%), Yb (99.99 wt.\%). The metals were alloyed in graphite crucibles using an induction furnace in an argon-purged (99.997 wt.\%) atmosphere. The alloys were tilt cast into a wedge-shaped (10:1 taper) copper mould at temperatures of approximately $100{ }^{\circ} \mathrm{C}$ to $150{ }^{\circ} \mathrm{C}$ above their liquidus to determine their critical casting thicknesses $\left(Z_{C}\right)$. For larger glass-forming compositions samples were suction cast in various diameters in $0.5 \mathrm{~mm}$ increments to determine their critical casting diameters $\left(D_{C}\right)$. Compression specimens $1.7 \mathrm{~mm}$ in diameter were fabricated by suction casting into a cylindrical copper mould, and the ends polished flat and parallel down to a SiC paper 1200 grit finish. The glassy structure was verified using X-ray diffraction (XRD) with a Phillips MRD instrument fitted with a $0.5 \mathrm{~mm}$ microcapillary tube and $\mathrm{Cu}$ Ka radiation source. Thermophysical data was determined by differential scanning calorimetry (DSC) using a Mettler Toledo DSC1/1700 calorimeter at a heating rate of $20^{\circ} \mathrm{C} / \mathrm{min}$. Vickers hardness testing was performed on selected alloys, using a Wolpert MXT- $\alpha$ microhardness tester, with a load of $500 \mathrm{~g}$ for $15 \mathrm{~s}$ over 20 indents. Compression tests were performed at a strain rate of $1 \times 10^{-4} \mathrm{~s}^{-1}$ using a Schenk screw-driven mechanical testing machine for up to 5 specimens per selected alloy.

\section{Results \& Discussion}

\subsection{Glass formation in the Mg-Cu-Yb ternary system}


Figure 1(a) and (b) shows the composition range of the newly discovered bulk glassforming alloys. Based on the DSC data generated in this work, reported phases and liquidus temperatures found in binary phase diagrams [38-40], and the similar Cu-CaMg ternary system [41], a liquidus iso-surface of $\mathrm{Mg}-\mathrm{Cu}-\mathrm{Yb}$ ternary system was also generated. It can be seen clearly that the $\mathrm{Mg}-\mathrm{Cu}-\mathrm{Yb}$ ternary system can now be perceived as one of the broadest ternary systems for glass formation, akin to the MgCu-Ca system, where bulk glass formation also occurs in each of the three elementbased regions, including an equiatomic element content BMG-forming composition.

Traditionally, bulk metallic glass formation compositions have been associated with the proximity of deep eutectic reactions with exceptionally lowered liquidus temperatures compared to surrounding composition space and very narrow freezing ranges. Such alloys physically require less heat to be drawn by a copper mould, hence faster cooling and a higher perceived critical casting size. The stability of a glass has historically been measured or compared by its thermophysical properties, which traditionally include the the reduced glass transition temperature $\left(T_{\mathrm{rg}}\right)$, introduced by Turnbull [42] defined as the glass transition temperature $\left(T_{\mathrm{g}}\right)$ divided by the liquidus temperature, $T_{1}$, which for good glass formers tends to be around 0.6. Similarly, the gamma $(\gamma)$ introduced by Lu and Liu equivalent to the crystallisation temperature $\left(T_{\mathrm{X}}\right)$ divided by $\left(T_{\mathrm{g}}+T_{\mathrm{l}}\right)$ which approached 0.5 for strong glass-formers [43].

In the Yb-based region, glass formation occurs in close proximity to the ternary eutectic reaction between the $\mathrm{Yb}$ solid solution, $\mathrm{Mg}_{2} \mathrm{Yb}$ and $\mathrm{CuYb}$. However, majority of bulk glass forming compositions with high GFA were found to lie in the Mg- and Cu-based regions in proximity to the liquidus lines/troughs between the $\mathrm{Cu}_{2} \mathrm{Mg}$, $\mathrm{Mg}_{2} \mathrm{Cu}$ and $\mathrm{Mg}_{2} \mathrm{Yb}$ liquidus phase fields. The largest glass produced in the $\mathrm{Mg}-\mathrm{Cu}-\mathrm{Yb}$ 
system was the $\mathrm{Mg}_{40.8} \mathrm{Cu}_{36.36} \mathrm{Yb}_{22.9}$ alloy with critical casting diameter $D_{\mathrm{C}}=3.5 \mathrm{~mm}$. which appears to lie directly on a ternary peritectic reaction, between these three specific phases. This indicates that bulk glasses may be formed far from ternary eutectic reactions, which has also only recently been seen in BMG-forming systems $[18,29,30]$. Coincidently, no bulk glasses are formed in proximity to the Mg-rich and Cu-rich eutectic reactions. These results somewhat contradict classic ideas about metallic glass formation, and the general usefulness of glass forming indicators, suggesting other aspects may have significant effect on glass-forming ability.

We show that there is good agreement between bulk glass formation and the simultaneously efficiently-packed composition regions highlighted in yellow in Figure $1(a)$ and glasses tend to increase in critical casting size when closer to the ideal packing lines (black dashed lines) and liquidus phenomena such as liquidus lines. It is also worth noting that the majority of bulk glasses occur towards the centre of the ternary diagrams where chemical entropy is highest.

It should also be pointed out that in all cases the critical casting thickness $\left(Z_{C}\right)$ determined by wedge casting is smaller than or equal to the critical casting diameter $\left(D_{\mathrm{C}}\right)$. This follows the trend observed in other systems where both $Z_{\mathrm{C}}$ and $D_{\mathrm{C}}$ have been determined for the same alloy [18, 29-32] and correlates with the geometric heat transfer relation, whereby $Z_{C}=0.7 D_{C}[44]$. Here the physical resolution in determining $D_{\mathrm{C}}$ is limited compared to $Z_{\mathrm{C}}$ by the incremental $0.5 \mathrm{~mm}$ diameter step size of our cylindrical moulds.

Examining the as-cast wedges, it was observed that certain alloys showed no effects of shrinkage cracking due to thermal contraction associated with cooling and crystallisation (i.e. stayed as a single wedge, with no cracks caused by thermal stress 
effects upon being cast); hence, these alloys were considered structurally relatively stable and were selected for compression testing.

\subsection{Mg-based BMGs}

Table 1 gives the critical casting thickness and diameter of the Mg-base glass forming alloys, along with their thermophysical properties and Vickers hardness where appropriate. The GFA appears to increase with increasing amounts of $\mathrm{Cu}$, and decreasing concentrations of $\mathrm{Yb}$ - for a given $\mathrm{Mg}$ concentration. The average $D_{\mathrm{C}}$ for these alloys is $2.0 \mathrm{~mm}$ and interestingly, only 3 compositions $\left(\mathrm{Mg}_{50} \mathrm{Cu}_{36.4} \mathrm{Yb}_{13.6}\right.$, $\mathrm{Mg}_{40.8} \mathrm{Cu}_{36.4} \mathrm{Yb}_{22.9}$, and $\left.\mathrm{Mg}_{36.4} \mathrm{Cu}_{27.3} \mathrm{Yb}_{36.4}\right)$ show as good or better GFA than the equiatomic composition.

Table 1: Critical casting thickness and thermophysical properties of Mg-based BMGs in the Mg-Cu-Yb system

\begin{tabular}{|c|c|c|c|c|c|c|c|c|c|c|}
\hline Composition & $\begin{array}{l}Z_{c} \\
(\mathrm{~mm})\end{array}$ & $\begin{array}{l}D_{c} \\
(\mathrm{~mm})\end{array}$ & $\begin{array}{l}T_{g} \\
\left({ }^{\circ} \mathrm{C}\right)\end{array}$ & $\begin{array}{l}T_{X} \\
\left({ }^{\circ} \mathrm{C}\right)\end{array}$ & $\begin{array}{l}\Delta T_{x} \\
\left({ }^{\circ} \mathrm{C}\right)\end{array}$ & $\begin{array}{l}T_{m} \\
\left({ }^{\circ} \mathrm{C}\right)\end{array}$ & $\begin{array}{l}T_{I} \\
\left({ }^{\circ} \mathrm{C}\right)\end{array}$ & $\overline{T_{r g}}$ & 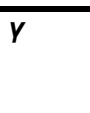 & HV0.5 \\
\hline $\mathrm{Mg}_{55} \mathrm{Cu}_{36} \mathrm{Yb}_{9}$ & 1.4 & 2.0 & 95 & 125 & 30 & 398 & 488 & 0.484 & 0.353 & $217 \pm 1.7$ \\
\hline $\mathrm{Mg}_{54.5} \mathrm{Cu}_{27.3} \mathrm{Yb}_{18.2}$ & 0.9 & 1.0 & 115 & 133 & 18 & 348 & 496 & 0.505 & 0.351 & $195 \pm 6.0$ \\
\hline $\mathrm{Mg}_{50} \mathrm{Cu}_{36.4} \mathrm{Yb}_{13.6}$ & 1.9 & 2.5 & 119 & 138 & 19 & 391 & 484 & 0.518 & 0.358 & $263 \pm 5.4$ \\
\hline $\mathrm{Mg}_{50} \mathrm{Cu}_{30} \mathrm{Yb}_{20}$ & 1.1 & 1.5 & 114 & 132 & 18 & 439 & 485 & 0.511 & 0.354 & $230 \pm 4.0$ \\
\hline $\mathrm{Mg}_{45.5} \mathrm{Cu}_{36.4} \mathrm{Yb}_{18.2}$ & 1.1 & 1.5 & 118 & 135 & 28 & 444 & 485 & 0.516 & 0.355 & $225 \pm 3.8$ \\
\hline $\mathrm{Mg}_{44} \mathrm{Cu}_{40.5} \mathrm{Yb}_{15.5}$ & 1.6 & 2.0 & 120 & 147 & 27 & 442 & 580 & 0.461 & 0.337 & $247 \pm 4.9$ \\
\hline $\mathrm{Mg}_{43} \mathrm{Cu}_{30} \mathrm{Yb}_{27}$ & 1.7 & 2.0 & 120 & 147 & 27 & 443 & 584 & 0.459 & 0.336 & $236 \pm 3.4$ \\
\hline $\mathrm{Mg}_{40.8} \mathrm{Cu}_{36.4} \mathrm{Yb}_{22.9}$ & 2.5 & 3.5 & 117 & 138 & 21 & 392 & 483 & 0.516 & 0.359 & $235 \pm 6.3$ \\
\hline $\mathrm{Mg}_{36.4} \mathrm{Cu}_{27.3} \mathrm{Yb}_{36.4}$ & 2.2 & 3.0 & 116 & 140 & 24 & 424 & 503 & 0.501 & 0.355 & $223 \pm 6.1$ \\
\hline $\mathrm{Mg}_{33.4} \mathrm{Cu}_{33.3} \mathrm{Yb}_{33.3}$ & 2.0 & 2.5 & 118 & 139 & 21 & 419 & 502 & 0.505 & 0.353 & $219 \pm 4.5$ \\
\hline
\end{tabular}

Figure 2a shows the differential scanning calorimetry (DSC) profiles of selected Mgbased BMGs. A clear glass transition $\left(T_{\mathrm{g}}\right)$ and subsequent crystallisation reaction can be seen in each instance, with considerable relaxation events (beta relaxation) prior to $T_{\mathrm{g}}$ evident in most compositions, as also seen in other Mg-Cu BMG alloys [45]. 
These Mg-based BMGs exhibit glass transition and crystallisation temperatures considerably lower than those of other Mg-Cu-RE BMGs, and are again more closely akin to the Mg-Cu-Ca [18] or even Mg-Zn-Ca [46] BMGS. Of particular note, the $\mathrm{Mg}_{55} \mathrm{Cu}_{36} \mathrm{Yb}_{9} \mathrm{BMG}$ has a very low $T_{\mathrm{g}}$ of $95^{\circ} \mathrm{C}$, but nonetheless this alloy has the largest supercooled liquid region (SCLR), $\Delta T_{\mathrm{x}}\left(=T_{\mathrm{x}}-T_{\mathrm{g}}\right)$ of $30^{\circ} \mathrm{C}$, of all the Mg-based BMGs, indicating the best processing window available for thermoplastic forming. Relative to the glass forming indicators $T_{\mathrm{rg}}$ and $\gamma, \mathrm{Mg}$-based alloys here exhibit quite low values compared to other glass-forming systems. This is likely due to the fact that these are not eutectic compositions and the melting reactions observed span temperature intervals from 41 to $148{ }^{\circ} \mathrm{C}$, with the $\mathrm{Mg}_{2} \mathrm{Cu}$ phase playing a dominant role in the final melting point of these alloys. However, the largest glass formers do indeed exhibit the larger values of $T_{\mathrm{rg}}$ and $\gamma$.

It is quite clear in Figure 1 that glass formation avoids higher liquidus temperature regions in closer proximity to high melting point binary intermetallics such as $\mathrm{Mg}_{2} \mathrm{Cu}$ and $\mathrm{Mg}_{2} \mathrm{Yb}$. Despite having good packing efficiency, it is also apparent that bulk glasses are not formed in close proximity to the saddle-point between $\mathrm{Mg}_{2} \mathrm{Cu}$ and $\mathrm{Mg}_{2} \mathrm{Yb}$ close to the popular $\mathrm{Mg}_{65} \mathrm{Cu}_{25} \mathrm{RE}_{10}$ composition space (a similar result can be observed in the $\mathrm{Mg}-\mathrm{Cu}-\mathrm{Ca}$ system). It is noted that in other trivalent rare earth binary systems such as $\mathrm{Mg}-\mathrm{Y}, \mathrm{Mg}-\mathrm{Gd}$ and $\mathrm{Mg}-\mathrm{Nd}$ the congruent solidification reaction observed for $\mathrm{Mg}_{2} \mathrm{Yb}$ and $\mathrm{Mg}_{2} \mathrm{Ca}$ does not exist; rather, a series of peritectic reactions occur with a range of other Mg-rich $\mathrm{Mg}-\mathrm{RE}$ intermetallics. This is a result of the specific electronic and topological differences between $\mathrm{Yb}$ and other RE elements, which is the likely reason that previous researchers were unable to obtain a bulk glass for the $\mathrm{Mg}_{65} \mathrm{Cu}_{25} \mathrm{Yb}_{10}$ composition [20,23]. Broadly speaking, the maximum $\mathrm{GFA} / D_{\mathrm{c}}$ of the $\mathrm{Mg}-\mathrm{Cu}-\mathrm{Yb} \mathrm{BMG}$ studied here are not as large as those found in the similar $\mathrm{Mg}-\mathrm{Cu}-\mathrm{Ca}$ system (e.g. $\mathrm{Mg}_{36.4} \mathrm{Cu}_{36.4} \mathrm{Ca}_{27.3}$ has a $D_{\mathrm{C}}=5 \mathrm{~mm}$ ). 
As mentioned previously, glass formation tends to prefer the $<10><14><17\rangle$ topological composition space, although glasses are also formed in the $<10><13><17>$ region and glass forming ability tends to increase as compositions approach liquidus troughs and the ideal packing efficiency lines. The largest glass former found in the $\mathrm{Mg}-\mathrm{Cu}-\mathrm{Yb}$ ternary system and the peritectic reaction also lie precisely on the $<10><14><17>$ ideal packing line, as do the larger sized glasses in the $\mathrm{Cu}$ - and Mg-based regions. This in effect highlights a connection between liquid stability, (represented locally by liquidus lines, peritectic and eutectic reactions), packing efficiency, specific cluster structures and glass-forming ability [10] which was also observed in the Mg-Cu-Ca system [18] and $\mathrm{Cu}-\mathrm{Zr}$ systems [11]. It also highlights that with respect to kinetics the greater the packing efficiency around each species (closer the composition lies to the ideal packing line in Figure 1) the higher the glass-forming ability.

Figure 2(b) shows the X-ray diffraction (XRD) spectra of selected Mg-based BMGs, indicating the characteristic diffuse halo of an amorphous microstructure at the centre section for the sample diameters indicated.

\subsection{Cu-based BMGs}

Table 2 presents the critical casting thickness and associated casting diameter, thermophysical properties and Vickers hardness of the Cu-based BMGs. The GFA of these alloys appears to reach a maximum when the $\mathrm{Cu}$ concentration is $36-45$ at\% and the Mg concentration is $31-36$ at. \%; however, GFA diminishes quickly with increasing $\mathrm{Yb}$ content. Figure 3a shows the DSC profiles of selected Cu-based BMGs. The alloys have glass stability similar to that of the Mg-based compositions, as shown by the narrow SCLR range between $15-29^{\circ} \mathrm{C}$, with $\Delta T_{\text {x, average }}=23.3^{\circ} \mathrm{C}$. The alloy $\mathrm{Cu}_{45.5} \mathrm{Mg}_{36.4} \mathrm{Yb}_{18.1}$ exhibits as good a $\Delta T_{\mathrm{x}}\left(29^{\circ} \mathrm{C}\right)$, similar to the best $\mathrm{Mg}$ - 
based BMG. A general trend is seen for fixed Cu concentrations (45 at.\%, 40 at.\% and 36 at.\%), where $T_{\mathrm{g}}$, and $T_{\mathrm{x}}$ increase with a decrease in $\mathrm{Mg}$ and an increase in $\mathrm{Yb}$ content (conversely the casting thickness increases with increasing $\mathrm{Mg} / \mathrm{decreasing}$ Yb). Two compositions, $\mathrm{Cu}_{40.9} \mathrm{Mg}_{36.4} \mathrm{Yb}_{22.7}$ and $\mathrm{Cu}_{36.4} \mathrm{Mg}_{27.2} \mathrm{Yb}_{36.4}$, have low freezing ranges $\left(60^{\circ} \mathrm{C}\right.$ and $27^{\circ} \mathrm{C}$, respectively) and both show a relatively narrow, single endothermic peak during melting, which indicates their proximity to the local peritectic reaction and liquidus lines between the $\mathrm{Cu}_{2} \mathrm{Mg}$ and $\mathrm{Mg}_{2} \mathrm{Cu}$ or $\mathrm{Mg}_{2} \mathrm{Yb}$ liquidus phase fields. $\mathrm{Cu}_{40.9} \mathrm{Mg}_{36.4} \mathrm{Yb}_{22.7}$ is one of the best $\mathrm{Cu}$-based glass formers, along with $\mathrm{Cu}_{45.5} \mathrm{Mg}_{36.4} \mathrm{Yb}_{18.1}, \mathrm{Cu}_{40.9} \mathrm{Mg}_{31.8} \mathrm{Yb}_{17.3}$ and $\mathrm{Cu}_{36.4} \mathrm{Mg}_{36.4} \mathrm{Yb}_{27.2}$ (all with a $D_{\mathrm{C}}$ of $3 \mathrm{~mm}$ ); these however, have large melting ranges of $118^{\circ} \mathrm{C}, 157^{\circ} \mathrm{C}$, and $122^{\circ} \mathrm{C}$ respectively.

Relative to the GFA indicators $T_{\mathrm{rg}}$ and $\gamma$, these Cu-based alloys also exhibit quite low values compared to other glass-forming systems, again due to their large distance from the local eutectic reactions. The correlation between critical casting size, $T_{\mathrm{rg}}$ and $\mathrm{Y}$ are quite poor in this region. Where the $\mathrm{Cu}_{36.4} \mathrm{Mg}_{27.2} \mathrm{Yb}_{36.4}$ alloy with the highest values of $T_{\mathrm{rg}}$ and $\mathrm{y}$ exhibits only marginal glass formation of $1 \mathrm{~mm}$ critical casting size, whereas the $\mathrm{Cu}_{45.5} \mathrm{Mg}_{36.4} \mathrm{Yb}_{18.1}, \mathrm{Cu}_{40.9} \mathrm{Mg}_{36.4} \mathrm{Yb}_{22.7}, \mathrm{Cu}_{40.9} \mathrm{Mg}_{31.8} \mathrm{Yb}_{27.3}$ and $\mathrm{Cu}_{36.4} \mathrm{Mg}_{36.4} \mathrm{Yb}_{27.2}$ alloys, all with critical casting diameters of $3 \mathrm{~mm}$ exhibit considerably lower values of $T_{\mathrm{rg}}$ and $\gamma$. This is an interesting observation, where liquidus temperature is decreasing with increasing $\mathrm{Yb}$ content as compositions continue down a liquidus trough, however GFA is also decreasing, even in close proximity to the efficient packing lines. This is thought to be a result of the specific crystallites being nucleated, whereby the larger glass-formers in this region lie well within the $\mathrm{Cu}_{2} \mathrm{Mg}$ liquidus phase field, where a small fraction of this higher melting point phase appears to increase the final liquidus temperatures of these particular alloys. Surprisingly, this does not seem to harm their glass-forming ability. However, 
glass forming ability drops sharply when approaching the $\mathrm{Cu}_{2} \mathrm{Yb}$ and $\mathrm{Cu}_{7} \mathrm{Yb}_{2}$ liquidus phase fields, e.g. GFA drops to only $1 \mathrm{~mm}$ at the $\mathrm{Cu}_{40.4} \mathrm{Mg}_{27.3} \mathrm{Yb}_{31.8}$ composition. This indicates that the nucleation and growth kinetics of the $\mathrm{Cu}_{2} \mathrm{Yb}$ and $\mathrm{Cu}_{7} \mathrm{Yb}_{2}$ phases is likely much higher, hence the lower GFA of these alloys.

Table 2: Critical casting thickness and thermophysical properties of $\mathrm{Cu}$-based BMGs in the Mg-Cu-Yb system

\begin{tabular}{|c|c|c|c|c|c|c|c|c|c|c|}
\hline Composition & $\begin{array}{l}Z_{C} \\
(\mathrm{~mm})\end{array}$ & $\begin{array}{l}D_{c} \\
(\mathrm{~mm})\end{array}$ & $\begin{array}{l}T_{g} \\
\left({ }^{\circ} \mathrm{C}\right)\end{array}$ & $\begin{array}{l}T_{X} \\
\left({ }^{\circ} \mathrm{C}\right)\end{array}$ & $\begin{array}{l}\Delta T_{x} \\
\left({ }^{\circ} \mathrm{C}\right)\end{array}$ & $\begin{array}{l}T_{m} \\
\left({ }^{\circ} \mathrm{C}\right)\end{array}$ & $\begin{array}{l}T_{I} \\
\left({ }^{\circ} \mathrm{C}\right)\end{array}$ & $T_{r g}$ & $r$ & HV0.5 \\
\hline $\mathrm{Cu}_{45.5} \mathrm{Mg}_{36.4} \mathrm{Yb}_{18.1}$ & 2.4 & 3.0 & 110 & 139 & 29 & 437 & 640 & 0.419 & 0.318 & $235 \pm 3.7$ \\
\hline $\mathrm{Cu}_{45.5} \mathrm{Mg}_{27.25} \mathrm{Yb}_{27.25}$ & 1.8 & 2.5 & 117 & 145 & 28 & 404 & 630 & 0.432 & 0.323 & $256 \pm .6 .4$ \\
\hline $\mathrm{Cu}_{45.5} \mathrm{Mg}_{22.7} \mathrm{Yb}_{31.8}$ & 0.8 & 1.0 & 127 & 152 & 25 & 375 & 607 & 0.455 & 0.332 & $242 \pm 7.1$ \\
\hline $\mathrm{Cu}_{40.9} \mathrm{Mg}_{36.4} \mathrm{Yb}_{22.7}$ & 2.3 & 3.0 & 112 & 139 & 27 & 447 & 663 & 0.411 & 0.312 & $225 \pm 5.6$ \\
\hline $\mathrm{Cu}_{40.9} \mathrm{Mg}_{31.8} \mathrm{Yb}_{27.3}$ & 2.2 & 3.0 & 120 & 140 & 20 & 421 & 637 & 0.432 & 0.317 & $232 \pm 4.0$ \\
\hline $\mathrm{Cu}_{40.4} \mathrm{Mg}_{27.3} \mathrm{Yb}_{31.8}$ & 0.7 & 1.0 & 139 & 154 & 15 & 385 & 604 & 0.470 & 0.331 & $221 \pm 1.3$ \\
\hline $\mathrm{Cu}_{36.4} \mathrm{Mg}_{36.4} \mathrm{Yb}_{27.2}$ & 2.2 & 3.0 & 117 & 141 & 24 & 434 & 556 & 0.470 & 0.340 & $251 \pm 4.7$ \\
\hline $\mathrm{Cu}_{36.4} \mathrm{Mg}_{31.8} \mathrm{Yb}_{31.8}$ & 1.3 & 1.5 & 123 & 143 & 20 & 418 & 573 & 0.468 & 0.335 & $227 \pm 7.5$ \\
\hline $\mathrm{Cu}_{36.4} \mathrm{Mg}_{27.2} \mathrm{Yb}_{36.4}$ & 0.8 & 1.0 & 133 & 156 & 23 & 443 & 470 & 0.546 & 0.373 & $217 \pm 7.4$ \\
\hline
\end{tabular}

These glasses belong to the $<10><14><17>$ topological family and generally exhibit a higher GFA when in close proximity to the ideal packing effieciency line in Figure 1(a) with the exception of when approaching the $\mathrm{Cu}_{2} \mathrm{Yb}$ and $\mathrm{Cu}_{7} \mathrm{Yb}_{2}$ liquidus phase fields. This exemplifies the role of kinetics again with respect to packing efficiency, where the largest glasses in the region are some distance from liquidus lines and have large solidification intervals and also the role of nucleation kinetics the competing crystalline phases, whereby the $\mathrm{Cu}_{2} \mathrm{Mg}$ phase appears to be much more sluggish than $\mathrm{Cu}_{2} \mathrm{Yb}$ and $\mathrm{Cu}_{7} \mathrm{Yb}_{2}$. Again, these $\mathrm{Cu}$-based $\mathrm{Cu}-\mathrm{Mg}-\mathrm{Yb}$ glasses exhibit a somewhat lower GFA than $\mathrm{Cu}-\mathrm{Mg}-\mathrm{Ca} B M G$ s, e.g. $\mathrm{Cu}_{36.4} \mathrm{Mg}_{31.8} \mathrm{Ca}_{31.8}: D_{\mathrm{C}}=8 \mathrm{~mm}$ [29] compared to $\mathrm{Cu}_{36.4} \mathrm{Mg}_{31.8} \mathrm{Yb}_{31.8}$ where $D_{\mathrm{C}}=1.5 \mathrm{~mm}$. Figure 3(b) shows the $\mathrm{XRD}$ spectra of selected Cu-based BMGs, indicating the glassy structure of the alloys. 


\subsection{Yb-based BMGs}

Table 3 gives the critical casting thickness and diameter of the Yb-base metallic glasses, their thermophysical properties and their Vickers hardness. The Yb-based region produces $\mathrm{BMGs}$ at a higher solvent concentration range $(33.3-70$ at. $\% \mathrm{Yb})$ than the Mg- and $\mathrm{Cu}$ - based regions. While the largest BMG found here had a maximum $D_{\mathrm{C}}$ of $2.5 \mathrm{~mm}$, for $\mathrm{Yb}_{60} \mathrm{Mg}_{20} \mathrm{Cu}_{20}$ further refinement could possibly yield glasses comparable to the Mg- and Cu-based regions in this system. The number of ternary $\mathrm{Yb}$-based BMGs is encouraging given the small number previously discovered in the $\mathrm{Yb}-\mathrm{Zn}-\mathrm{Mg}-(\mathrm{Cu})$ system [28]. The largest glass forming alloy in the Yb-rich region found in this work was located closest to the estimated eutectic reaction, which is a phenomenon commonly observed in many bulk glass-forming systems.

Table 3: Critical casting thickness and thermophysical properties of $\mathrm{Yb}$-based BMGs in the Mg-Cu-Yb system

\begin{tabular}{|c|c|c|c|c|c|c|c|c|c|c|}
\hline Composition & $\begin{array}{l}Z_{C} \\
(\mathrm{~mm})\end{array}$ & $\begin{array}{l}D_{c} \\
(\mathrm{~mm})\end{array}$ & $\begin{array}{l}{ }^{*} T_{g} \\
\left({ }^{\circ} \mathrm{C}\right)\end{array}$ & $\begin{array}{l}T_{X} \\
\left({ }^{\circ} \mathrm{C}\right)\end{array}$ & $\begin{array}{l}\Delta \boldsymbol{T}_{\boldsymbol{x}} \\
\left({ }^{\circ} \mathrm{C}\right)\end{array}$ & $\begin{array}{l}T_{m} \\
\left({ }^{\circ} \mathrm{C}\right)\end{array}$ & $\begin{array}{l}T_{I} \\
\left({ }^{\circ} \mathrm{C}\right)\end{array}$ & $\overline{T r g}$ & 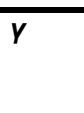 & HV0.5 \\
\hline $\mathrm{Yb}_{70} \mathrm{Mg}_{10} \mathrm{Cu}_{20}$ & 0.6 & - & 136 & 155 & 19 & 443 & 472 & 0.549 & 0.371 & - \\
\hline $\mathrm{Yb}_{65} \mathrm{Mg}_{17.5} \mathrm{Cu}_{17.5}$ & 1.2 & 1.5 & 122 & 142 & 20 & 417 & 457 & 0.541 & 0.369 & $159 \pm 6.8$ \\
\hline $\mathrm{Yb}_{60} \mathrm{Mg}_{20} \mathrm{Cu}_{20}$ & 1.9 & 2.5 & 140 & 158 & 18 & 412 & 438 & 0.581 & 0.383 & $163 \pm 4.0$ \\
\hline $\mathrm{Yb}_{60} \mathrm{Mg}_{15} \mathrm{Cu}_{25}$ & 0.7 & 1.0 & 144 & 160 & 16 & 411 & 468 & 0.563 & 0.374 & $168 \pm 3.9$ \\
\hline $\mathrm{Yb}_{60} \mathrm{Mg}_{13} \mathrm{Cu}_{27}$ & 1.0 & 1.0 & 138 & 158 & 20 & 404 & 468 & 0.555 & 0.374 & $161 \pm 4.6$ \\
\hline $\mathrm{Yb}_{55} \mathrm{Mg}_{30} \mathrm{Cu}_{15}$ & 1.2 & 1.5 & 136 & 153 & 17 & 406 & 474 & 0.548 & 0.369 & $163 \pm 4.5$ \\
\hline $\mathrm{Yb}_{55} \mathrm{Mg}_{25} \mathrm{Cu}_{20}$ & 1.3 & 1.5 & 146 & 161 & 15 & 413 & 475 & 0.560 & 0.372 & $165 \pm 4.3$ \\
\hline $\mathrm{Yb}_{55} \mathrm{Mg}_{20} \mathrm{Cu}_{25}$ & 1.1 & 1.5 & 153 & 170 & 17 & 413 & 501 & 0.550 & 0.369 & $170 \pm 5.1$ \\
\hline $\mathrm{Yb}_{55} \mathrm{Mg}_{15} \mathrm{Cu}_{30}$ & 0.4 & - & 158 & 174 & 16 & 408 & 625 & 0.480 & 0.336 & - \\
\hline $\mathrm{Yb}_{50} \mathrm{Mg}_{30} \mathrm{Cu}_{20}$ & 0.8 & 1.0 & 151 & 166 & 15 & 407 & 464 & 0.575 & 0.378 & $175 \pm 3.1$ \\
\hline $\mathrm{Yb}_{50} \mathrm{Mg}_{25} \mathrm{Cu}_{25}$ & 0.8 & 1.0 & 146 & 169 & 23 & 412 & 453 & 0.577 & 0.386 & $179 \pm 3.5$ \\
\hline $\mathrm{Yb}_{45} \mathrm{Mg}_{25} \mathrm{Cu}_{30}$ & 0.6 & - & 151 & 168 & 17 & 433 & 477 & 0.565 & 0.376 & - \\
\hline $\mathrm{Yb}_{40} \mathrm{Mg}_{30} \mathrm{Cu}_{30}$ & 0.8 & 1.0 & 142 & 161 & 19 & 438 & 462 & 0.565 & 0.377 & $217 \pm 3.3$ \\
\hline
\end{tabular}


Figure 4(a) shows the DSC profiles of selected Yb-based BMGs. The Yb-based BMGs display considerably higher $T_{\mathrm{g}}$ than the $\mathrm{Mg}$ - and Cu-based compositions, with a $T_{\mathrm{g}}$ range between $122-153^{\circ} \mathrm{C}$, compared to $95-120^{\circ} \mathrm{C}$ for Mg alloys, and $110-$ $139^{\circ} \mathrm{C}$ for $\mathrm{Cu}$ alloys. However, the $\mathrm{Yb}$-compositions have small SCLR, ranging from $12-23^{\circ} \mathrm{C}\left(\Delta T_{\text {x, average }}=17.2^{\circ} \mathrm{C}\right)$, which is slightly smaller than the $\mathrm{Cu}$-based compositions and much smaller than the Mg-based compositions.

In contrast to $\mathrm{Yb}-\mathrm{Zn}-\mathrm{Mg}-(\mathrm{Cu}) \mathrm{BMGs}$ [28], $\mathrm{Yb}-\mathrm{Mg}-\mathrm{Cu}$ glasses exhibit higher thermophysical values. $\mathrm{Yb}-\mathrm{Zn}-\mathrm{Mg}-\mathrm{Cu}$ BMGs have values of $T_{\mathrm{g}}$ that range between 74 to $111^{\circ} \mathrm{C}, T_{\mathrm{x}}: 113$ to $146{ }^{\circ} \mathrm{C}$, and $T_{\mathrm{M}}: 356$ to $384.5^{\circ} \mathrm{C}$ whereas the lowest value of $T_{\mathrm{g}}$ among the $\mathrm{Yb}-\mathrm{Mg}-\mathrm{Cu} \mathrm{BMGs}$ is $136{ }^{\circ} \mathrm{C}$ for $\mathrm{Yb}_{70} \mathrm{Mg}_{10} \mathrm{Cu}_{20}$. Of course, the inclusion of a low melting temperature $\mathrm{Zn}\left(419^{\circ} \mathrm{C}\right)$ is thought to lead to these lower thermophysical values. It is also worth noting that these $\mathrm{Yb}$-based alloys also have considerably higher $T_{\mathrm{g}}$ and $T_{\mathrm{x}}$ values than Ca-based BMGs from the $\mathrm{Ca}-\mathrm{Mg}-\mathrm{Cu}$ system. Furthermore, Ca-based BMGs from the Ca-Mg-Cu ternary system form much larger bulk glasses (up to $10 \mathrm{~mm}$ in diameter) [34]. In terms of mixing enthalpies, the Ca-containing bond pairs are nearly identical to those of $\mathrm{Yb}(\mathrm{Cu}-\mathrm{Yb}$ : $12 \mathrm{KJmol}^{-1}$ compared to $\mathrm{Ca}-\mathrm{Cu}:-13 \mathrm{KJmol}^{-1}$ and $\mathrm{Mg}-\mathrm{Yb}:-6 \mathrm{KJmol}^{-1}$ compared to CaMg: $-6 \mathrm{KJmol}^{-1}$ ), which indicates that there may be another reason for lower GFA and higher $T_{\mathrm{g}}$ and $T_{\mathrm{x}}$ values. The $\mathrm{Yb}$-based BMGs tend to exhibit thermophysical properties more closely akin to Lanthanide-based BMGs such as La-Al-Cu [47], indicating that in the $\mathrm{Yb}$-based region $\mathrm{Yb}$ may be interacting in a more trivalent manner, less like divalent $\mathrm{Ca}$, or that the f-band electrons (which are absent in $\mathrm{Ca}$ bonds) are interacting differently in this bonding state. Furthermore, higher $\mathrm{Cu}$ content gives rise to higher $T_{\mathrm{g}}$ and $T_{\mathrm{x}}$ values than those higher in $\mathrm{Mg}$ - probably a result of the higher heat of mixing (binding potential) between the $\mathrm{Yb}-\mathrm{Cu}$ pair as opposed to the $\mathrm{Yb}-\mathrm{Mg}$ pair. 
Being in close proximity to the ternary eutectic with narrow melting intervals and higher values of $T_{\mathrm{g}}$, the $\mathrm{Yb}$-based glasses have considerably higher values of $T_{\mathrm{rg}}$ and $\mathrm{Y}$ than those of the Mg- and Cu-based BMGs in this system. This is closer to what one would expect for good glass-formation, where $T_{\mathrm{rg}}$ and $\gamma$ values are as high as 0.58 and 0.38 for the $\mathrm{Yb}_{60} \mathrm{Mg}_{20} \mathrm{Cu}_{20}$ alloy which had the highest value of $D_{\mathrm{c}}$ of the $\mathrm{Yb}$ based alloys studied. Despite these considerably higher values of $T_{\mathrm{rg}}$ and $\mathrm{y}$, glass forming ability did not exceed that in the Mg- and Cu-based composition regions.

According to the packing efficiency model, these glasses correspond to the predicted $<9><12><15>$ efficient packing region [10] and coincidently the eutectic reaction and largest glass former lie directly on the ideal packing-efficiency line (dashed black line in Fig 1(a) which further supports the topological model in predicting liquid stability and glass-forming ability. Figure $4 b$ shows the XRD spectra of selected Yb-based BMGs, typical of amorphous alloys.

\subsection{Mechanical properties}

Figure 5 shows an average contour plot of the variation in Vickers hardness over the glass forming range. Associated errors are included in Tables 1-3. It can be clearly seen that as the $\mathrm{Yb}$-content is increased the BMGs become softer. Despite local minor fluctuations in hardness, one interesting result is a local 'hard region' located in close proximity to the $\mathrm{Cu}_{36.4} \mathrm{Mg}_{36.4} \mathrm{Yb}_{27.2}$ composition, and a 'soft trough' extending below this into a more copper-rich composition space. Similar fluctuations wereobserved by Laws et al. in the Cu-based region of the $\mathrm{Ca}-\mathrm{Cu}-\mathrm{Mg}$ ternary system - in comparable composition ranges if $\mathrm{Ca}$ is exchanged for $\mathrm{Yb}$ [29]. These fluctuations were found to correspond to fluctuations in alloy density, where a higher density resulted in higher alloy hardness. This was attributed to local structural packing efficiency and the possibility of medium range order between specific atomic 
clusters (in that particular case $\mathrm{Cu}$-centred clusters). It is also possible that this local hard region and soft trough could correspond to the structural transition from the $<10><13><17>$ topology to the $<10><14><17>$ topology as both $\mathrm{Cu}$ and Mg are increased. This indicates that hardness (or strength) in these BMGs may not be dictated purely by systematic changes in chemistry, and that local structure plays an important role.

Figure 6 shows stress-strain curves of selected alloys tested in uniaxial compression. Several alloy compositions which appeared more resistant to fracture during handling were selected for compression testing.

It was found that the equiatomic $\mathrm{Mg}_{33.4} \mathrm{Cu}_{33.3} \mathrm{Yb}_{33.3}$ BMG composition displays a fracture strength $\left(\sigma_{f}\right)$ of $455 \mathrm{MPa}$. In comparison, lowering the Cu content slightly (with equal increases in $\mathrm{Mg}$ and $\mathrm{Yb}$ content) to $\mathrm{Mg}_{36.36} \mathrm{Cu}_{27.27} \mathrm{Yb}_{36.36}$ gives a slight increase in strength of $488 \mathrm{MPa}$. A similar composition shift to lower $\mathrm{Yb}$ content in the $\mathrm{Cu}_{36.4} \mathrm{Mg}_{36.4} \mathrm{Yb}_{27.2} \mathrm{BMG}$ results in a significant strength increase to $\sigma_{\mathrm{f}}=558 \mathrm{MPa}$. The alloy with the highest GFA found, $\mathrm{Mg}_{40.8} \mathrm{Cu}_{36.4} \mathrm{Yb}_{22.9}$, displays the highest fracture strength of alloys tested at $612 \mathrm{MPa}$; the composition also has the maximum possible Cu content (36 at.\%) for bulk glass formation. Conversely, the largest GFA Yb-based composition, $\mathrm{Yb}_{60} \mathrm{Mg}_{20} \mathrm{Cu}_{20}$, displays the lowest strength value of the alloys tested, at $\sigma_{\mathrm{f}}=418 \mathrm{MPa}$. Typically, the selected compositions exhibit the usual elasticity range for BMGs, between $1.5-2 \%$. These strength values tend to correlate with the hardness profile of the system, and fracture strength is generally $2.5-3$ times the hardness value [46].

Relatively speaking, these BMGs exhibit low fracture strengths when compared to most Mg-based BMGs or the $\mathrm{Ca}-\mathrm{Cu}-\mathrm{Mg}$ BMGs in both the Cu-based and Ca-based regions. The general lower hardness of Yb-alloys can be attributed to 
elastic correlations of elemental Ytterbium. As noted by Wang et al. [28], Yb-based $\mathrm{Yb}-\mathrm{Zn}-\mathrm{Mg}(-\mathrm{Cu}) \mathrm{BMGs}$ have generally low mechanical properties, such as low elastic modulus, Poisson's ratio and Vickers hardness - an occurrence which is also exhibited by these new Yb-based BMGs. On the other hand, increasing the amount of $\mathrm{Cu}$ relative to the $\mathrm{Yb}$ content generally leads to increased hardness. This may be due to the increase in the number of $\mathrm{Cu}-\mathrm{Yb}$ pairs, which possess the highest negative heat of mixing among the atom pairs present in the system.

\section{Concluding summary}

An ensemble of Mg-based, Cu-based, and Yb-based BMG-forming alloys was discovered over a broad composition range using a topological efficient atomic packing model [10]. The maximum critical casting diameter found within the system was $3.5 \mathrm{~mm}$ for the $\mathrm{Mg}$-based $\mathrm{Mg}_{40.8} \mathrm{Cu}_{36.4} \mathrm{Yb}_{22.9}$ alloy. However, several Cu-based compositions had a critical casting diameter of $3 \mathrm{~mm}$ and the Cu-based glasses exhibited higher GFA over a broader composition range. With regard to GFA, further improvements in critical casting size may be possible in this system through composition optimisation.

With respect to classic glass-forming indicators, such as $T_{\text {rg }}$ and $\gamma$, these alloys only loosely follow trends of glass forming tendency, where these values for the Yb-based BMGs indicate a high glass forming tendency, their critical casting sizes were generally considerably smaller than those of the Mg- and Cu-based BMGs which exhibited much lower values of $T_{\mathrm{rg}}$ and $\gamma$. This is largely owing to the compositional distance of the Mg-and Cu-based BMGs from deep eutectic reactions and their broad solidus-liquidus intervals. Glass formation and glass-forming ability was also found to be highly dependent on the corresponding liquidus phase fields within which the alloys lie, whereby those in the $\mathrm{Cu}_{2} \mathrm{Mg}$ liquidus phase field exhibited the highest GFA 
which quickly diminishes as compositions approach the $\mathrm{Cu}_{2} \mathrm{Yb}$ and $\mathrm{Cu}_{7} \mathrm{Yb}_{2}$ liquidus phase fields.

The Mg- and Cu-based glasses were determined to belong to the $<10><13><17\rangle$ and $<10><14><17>$ topological families, forming glasses in this pre-determined composition space. The Yb-based BMGs were found to show lower glass forming sizes, forming BMGs in the $<9><12><15>$ topological composition space. Glassforming ability tended to increase as compositions approached the ideal topological atomic packing conditions (ideal packing efficiency lines) in this alloy system. These results highlight the effectiveness of using topological models to predict glass-forming compositions, particularly in unexplored systems where no or inconclusive ternary phase diagrams exist.

While it has been demonstrated that in terms of GFA, Yb is a viable topological substitute for $\mathrm{Ca}$ in the $\mathrm{Mg}-\mathrm{Cu}-\mathrm{Ca}$ ternary system, further investigation or modelling could be used to explain the lesser glass-forming ability of the $\mathrm{Mg}-\mathrm{Cu}-\mathrm{Yb}$ ternary system. It is also anticipated that multi-component systems beyond this ternary such as $\mathrm{Mg}-\mathrm{Cu}-\mathrm{Ag}-\mathrm{Yb}, \mathrm{Mg}-\mathrm{Cu}-\mathrm{Zn}-\mathrm{Yb}$ and $\mathrm{Mg}-\mathrm{Cu}-\mathrm{Ni}-\mathrm{Yb}$ will likely yield BMGs, which are currently being synthesised by our research group.

\section{Acknowledgements}

This work was supported by the Swiss National Science Foundation (SNF Grant No. 200020-153103) and the Australian Research Council (Grant No. DE120102588).

\section{References}

[1] W. Klement, R. H. Willens, P. Duwez, Non-crystalline structure in solidified goldsilicon alloys, Nature 187 (1960) 869-870. 
[2] D. Shiyan, Y. Liu, Y. Li, Z. Liu, S. Sohn, F.J. Walker, J. Schroers, Combinatorial development of bulk metallic glasses, Nat. Mater. 13 (2014) 494-500.[3] Y.Q. Cheng, E. Ma, Atomic-level structure and structure-property relationship in metallic glasses, Prog. Mater. Sci. 56 (2011) 379-473.

[4] E. Perim, D. Lee, $, \underline{Y . ~ L i u}, \underline{\text { C. Toher }}, \underline{P . \text { Gong, Y. Li }}, \underline{\text { W. N. Simmons, }}, \underline{\text { O. Levy, J. J. }}$

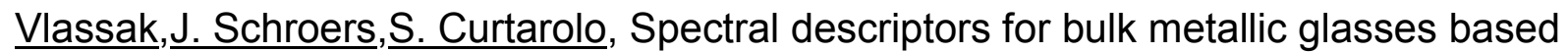
on the thermodynamics of competing crystalline phases Nat.Commun.7 (2016)12315.

[5] R. Mahjoub, N.E. Hamilton, K.J. Laws, M. Ferry, Softening of phonon spectra and glass forming ability, njp Comput.Mater.2 (2016) 16029.

[6] R. Mahjoub, K.J. Laws, N.E. Hamilton, D. Granata, M. Ferry, An atomic-scale insight into the effects of hydrogen alloying on the glass-forming ability and ductility of Zr-based bulk metallic glasses, Comput. Mater. Sci. 125 (2016). 197-205.

[7] A. Takeuchi, A. Inoue, Calculations of amorphous-forming composition range for ternary alloy systems and analysis of stabilization of amorphous phase and amorphous-forming ability, Mater. Trans. JIM 24 (2001) 1435-1444.

[8] A. Zhu, S. J. Poon, G. J. Shiflet, On glass formability of Al-Gd-Ni (Fe), Scr. Mater. 50 (2004) 1451-1455.

[9] D. B. Miracle, A structural model for metallic glasses, Nat. Mater. 3 (2004) 697702

[10] K.J. Laws, D.B. Miracle, M. Ferry, A predictive structural model for bulk metallic glasses, Nat. Commun. 6 (2015) 8123.

[11] C. Dong, Q. Wang, J. B. Qiang, Y. M. Wang, N. Jiang, G. Han, Y. H. Li, J. Wu, J.H. Xia,From clusters to phase diagrams: composition rules of quasicrystals and bulk metallic glasses, J. Phys. D: Appl. Phys.40 (2007) R273-R291. 
[12] A. Inoue, A. Kato , T. Zhang, S.G. Kim, T. Masumoto, Mg-Cu-Y amorphous alloys with high mechanical strengths produced by a metallic mold casting method, Mater Trans JIM, 32 (1991) 609-616.

[13] H. Men, D.H. Kim, Fabrication of ternary Mg-Cu-Gd bulk metallic glass with high glass-forming ability under air atmosphere, J. Mater. Res. 18 (2003) 1502-1504.

[14] K.Q. Qiu, Q.F. Li, Y.L. Ren, W.H. Jiang, X.G. Yuan, Glass-forming ability for MgCu-Nd alloys, Metall. Mater. Trans. A 39a (2008) 1882-1887.

[15] X.F. Wu, Y. Kang, F.F. Wu, K.Q. Qiu, L.K. Meng, Formation of ternary Mg-CuDy bulk metallic glasses, Bull. Mater. Sci. 34 (2011) 1507-1510.

[16] X.K. Xi, D.Q. Zhao, M.X. Pan, W.H. Wang, Highly processable Mg65Cu25Tb10 bulk metallic glass, J. Non. Cryst. Solids 344 (2004) 189-192.

[17] W.Y. Liu, H.F. Zhang, Z.Q. Hu, H. Wang, Formation and mechanical properties of Mg65Cu25Er10 and Mg65Cu15Ag10Er10 bulk amorphous alloys, J. Alloys Compd. 397 (2005) 202-206.

[18] K.J. Laws, K.F. Shamlaye, J.D. Cao, J.P. Scicluna, M. Ferry, Locating new Mgbased bulk metallic glasses free of rare earth elements, J. Alloys Compd. 542 (2012) $105-110$.

[19] A. Inoue, T. Masumoto, Mg-based amorphous alloys, Mater. Sci. Eng. A 173 (1993) 1-8.

[20] F.Q. Guo, S.J. Poon, X. Gu, G.J. Shiflet, Low-density Mg-rich metallic glasses with bending ductility, Scr. Mater. 56 (2007) 689-692.

[21] H. Ma, L.L. Shi, J. Xu, Y. Li, E. Ma, Discovering inch-diameter metallic glasses in three-dimensional composition space, Appl Phys Lett 87 (2005) 181915. [22] X.K. Xi, D.Q. Zhao, M.X. Pan, W.H. Wang, On the criteria of bulk metallic glass formation in MgCu-based alloys, Intermetallics 13 (2005) 638-641. 
[23] A.A. Tsarkov, E.N. Zanaeva, A. Yu, S.V. Ketov, D.V. Louzguine-luzgin, Crystallization kinetics of Mg-Cu-Yb-Ca-Ag metallic glasses, Mater. Charact. 111 (2016) $75-80$.

[24] A. Inoue, W. Zhang, T. Zhang, K. Kurosaka, High-strength Cu-based bulk glassy alloys in $\mathrm{Cu}-\mathrm{Zr}$-Ti and $\mathrm{Cu}-\mathrm{Hf}-\mathrm{Ti}$ ternary systems, Acta. Mater. 49 (2001) 26452652.

[25] A. Inoue, W. Zhang, T. Zhang, K. Kurosaka, Cu-based bulk glassy alloys with high tensile strength of over 2000 MPa, J. Non-Cryst. Solids 304 (2002) 200-209. [26] J. Eckert, J. Das, K.B. Kim, F. Baier, High strength ductile Cu-base metallic glass, Intermetallics 14 (2006) 876-881.

[27] K.J. Laws, K.F. Shamlaye, B. Gun, M.Ferry, Synthesis of copper-based bulk metallic glasses in the ternary Cu-Mg-Ca system, J. Alloys Compd. 486 (2009) 2729.

[28] J.Q. Wang, W.H. Wang, H.Y. Bai, Soft ytterbium-based bulk metallic glasses with string liquid characteristic by design, Appl. Phys. Lett. 94 (2009) 041910. [29] K.J. Laws, K.F. Shamlaye, K. Wong, B. Gun, M.Ferry, Prediction of glassforming compositions in metallic systems: copper-based bulk metallic glasses in the Cu-Mg-Ca system, Metall. Mater. Trans. A 41A (2010) 1699-1705.

[30] K.J. Laws, K.F. Shamlaye, M. Ferry, Synthesis of Ag-based bulk metallic glass in the Ag-Mg-Ca- [Cu] alloy system, J. Alloys Compd. 513 (2012) 10-13.

[31] K.J. Laws, J.D. Cao, C. Reddy, K.F. Shamlaye, B. Gun, M. Ferry, Ultramagnesium-rich, low-density Mg-Ni-Ca bulk metallic glasses, Scr. Mater. 88 (2014) $37-40$.

[32] K.J. Laws, K.F. Shamlaye, B. Gun, K. Wong M. Ferry, The prediction of glassforming compositions in metallic systems - the development of new bulk metallic glasses, Mater. Sci. Forum 638-642 (2010) 1637-1641. 
[33] S. Cotton, Lanthanide and Actinide Chemistry, John Wiley \& Sons Ltd., Chichester, 2006.

[34] O.N. Senkov, J.M. Scott, D.B. Miracle, Composition range and glass forming ability of ternary Ca-Mg-Cu bulk metallic glasses, J. Alloys Compd. 424 (2006) 394399.

[35] K. Amiya, A. Inoue, Formation and thermal stability of $\mathrm{Ca}-\mathrm{Mg}-\mathrm{Ag}-\mathrm{Cu}$ bulk glassy alloys, Mater. Trans. JIM 43 (2002) 2578-2581.

[36] D.B. Miracle, W.S. Sanders, O.N. Senkov, The influence of efficient atomic packing on the constitution of metallic glasses, Philos. Mag. 83 (2003) 2409-2428. [37] D.B. Miracle, O.N. Senkov, W.S. Sanders, K.L. Kendig, Structure-forming principles for amorphous metals, Mater. Sci. Eng. A 375-377 (2004) 150-156.

[38] H. Okamoto, Cu-Mg (Copper-Magnesium), J. Phase Equilib. 13 (1992) 213-214. [39] P.R. Subramanian, D.E. Laughlin, Cu-Yb (Copper-Ytterbium), in: T.B. Massalski (Ed.), Binary alloy phase diagrams, second ed, ASM International, Materials Park, Ohio, 1990, $1505-1508$.

[40] C. Guo, Z. Du, Thermodynamic optimization of the Mg-Tb and Mg-Yb systems, J. Alloy Compd. 422 (2006) 102-108.

[41] K.M. Myles, The ternary system copper-magnesium-calcium, J. Less-Common Met. 20 (1970) 149-54.

[42] D. Turnbull, Under What Conditions can a Glass be Formed?, Contemp. Phys.10 (1969) 473-88.

[43] Z.P. Lu, C.T. Liu:, A new glass-forming ability criterion for bulk metallic glasses, Acta. Mater. 50 (2002) 3501-12.

[44] K.J. Laws, B. Gun, M. Ferry; Influence of casting parameters on the critical casting size of bulk metallic glass, Metall. Mater. Trans. A. 40A (2009) 2377-2387. 
[45] K.J. Laws, D. Granata, J.F. Löffler, Alloy design strategies for sustained ductility in Mg-based amorphous alloys - tackling structural relaxation, Acta Mater. 103 (2016) 735-745.

[46] X. Gu, G.J. Shiflet, F.Q. Guo, S.J. Poon, Mg-Ca-Zn bulk metallic glasses with high strength and significant ductility, J. Mater. Res. (2005) 1935-1938.

[47] Y. Zhang, Y. Li, H. Tan, G.L. Chen, H.A. Davies, Glass forming ability criteria for La-Al-(Cu,Ni) alloys, J. Non-Cryst. Solids 352 (2006) 5482-5486. 


\section{Figure Captions}

Figure 1: Composition range and relative glass-forming ability in the $\mathrm{Mg}-\mathrm{Cu}-\mathrm{Yb}$ system with respect to (a) predicted glass-forming regions (yellow) and topological families [10] and (b) the liquidus iso-surface and phase fields in accordance with DSC data and associated phase diagrams [38-41].

Figure 2: Selected (a) DSC and (b) XRD traces of Mg-based metallic glasses in the Mg-Cu-Yb system

Figure 3: Selected (a) DSC and (b) XRD traces of Cu-based metallic glasses in the $\mathrm{Mg}-\mathrm{Cu}-\mathrm{Yb}$ system

Figure 4: Selected (a) DSC and (b) XRD traces of Yb-based metallic glasses in the Mg-Cu-Yb system

Figure 5: A contour plot of Vickers hardness Vs composition for the $\mathrm{Mg}-\mathrm{Cu}-\mathrm{Yb}$ metallic glasses

Figure 6: Stress strain curves of selected Mg-Cu-Yb bulk metallic glasses 

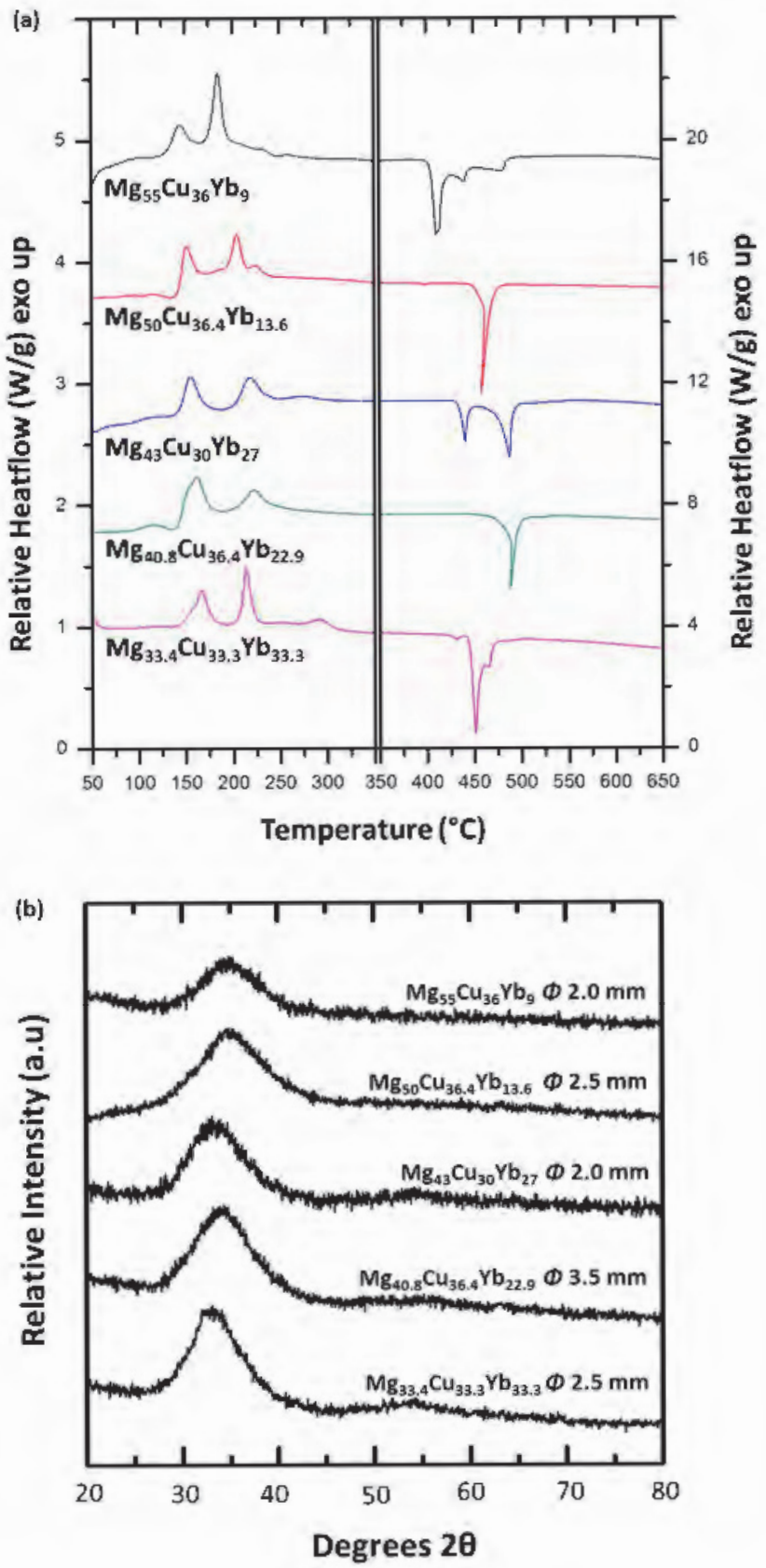

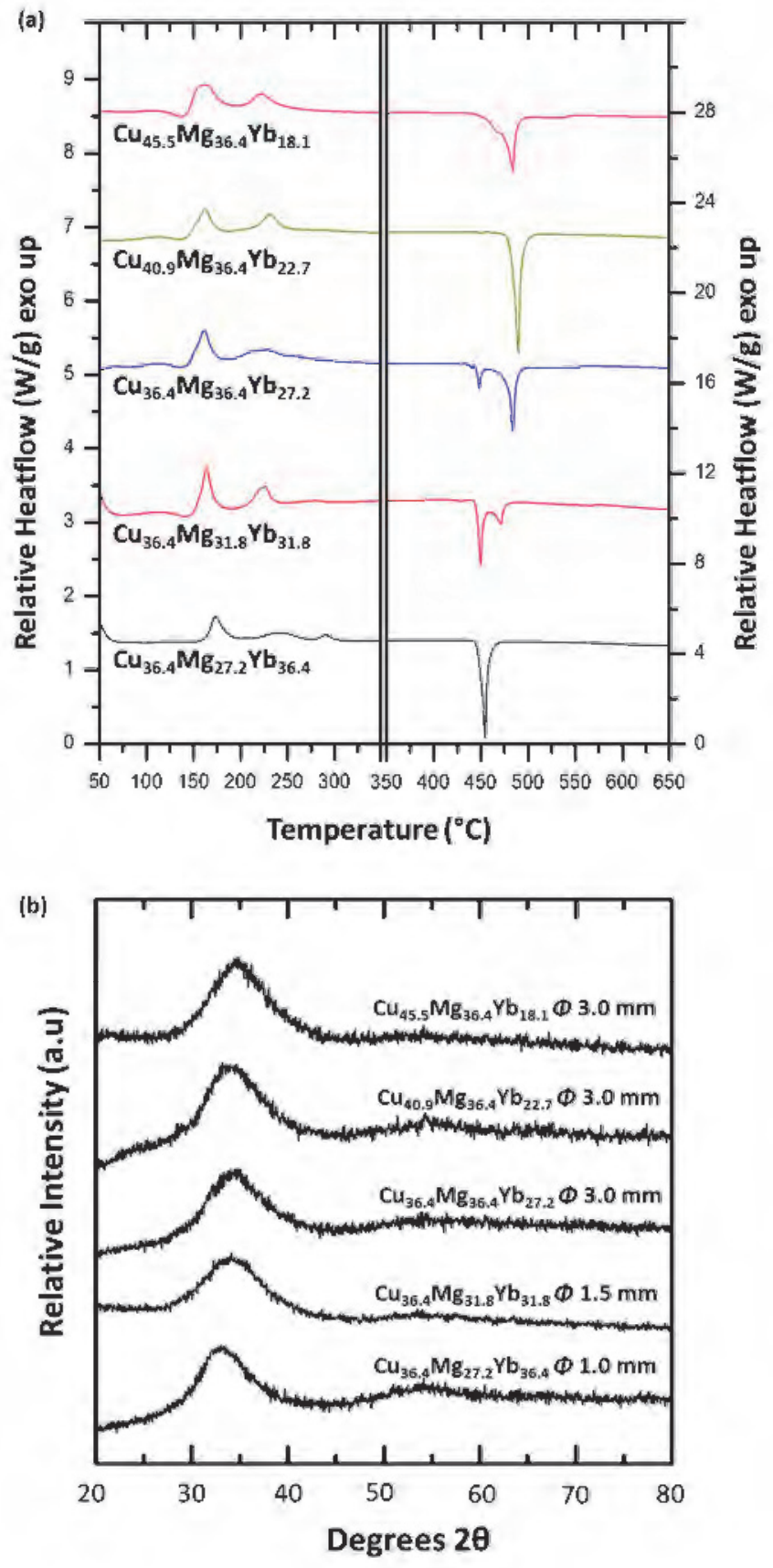


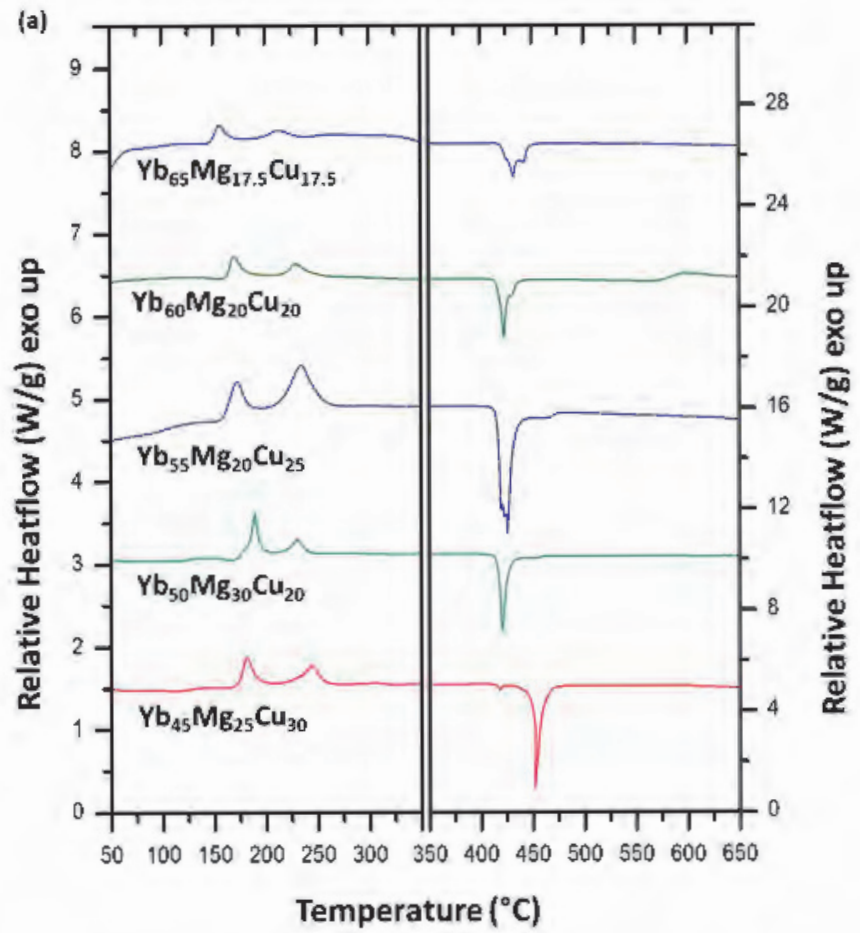

(b)

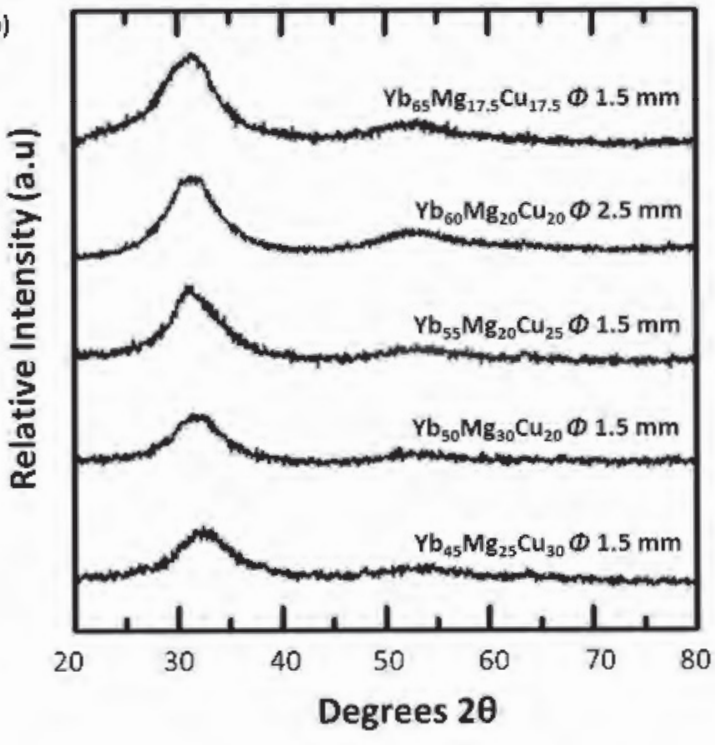




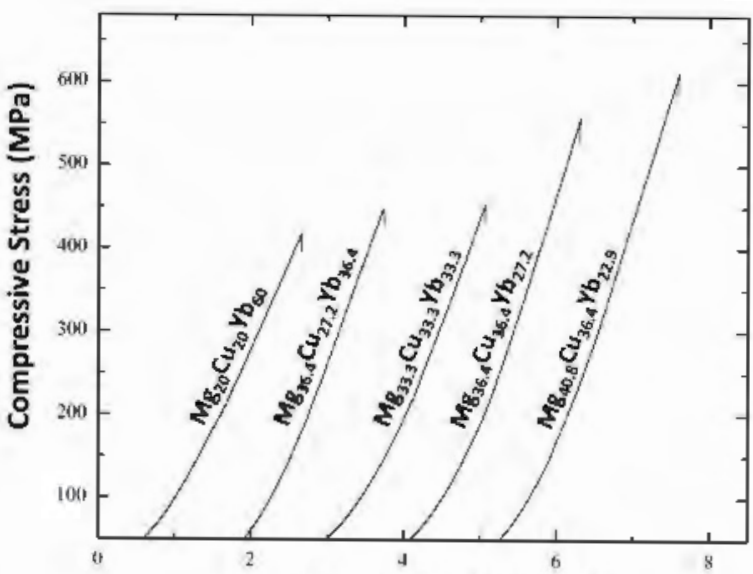

Compressive Strain (\%) 


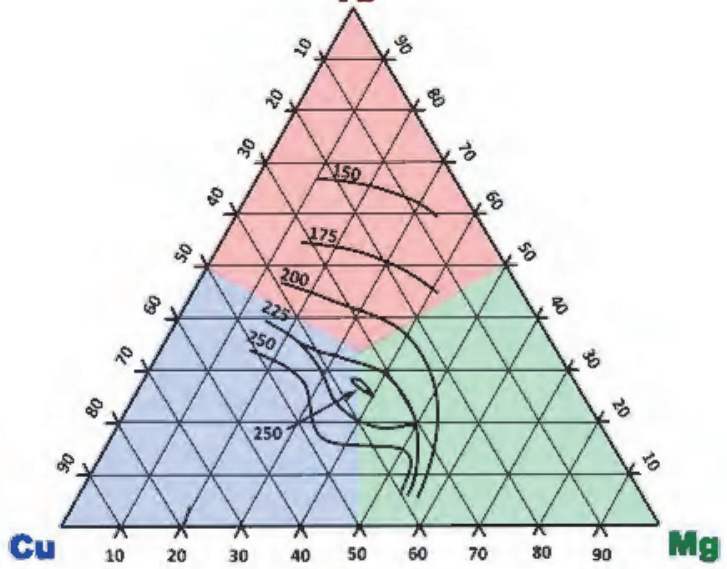


Composition, efficient packing \& glass forming ability Contour plot of Vickers hardness Vs. composition
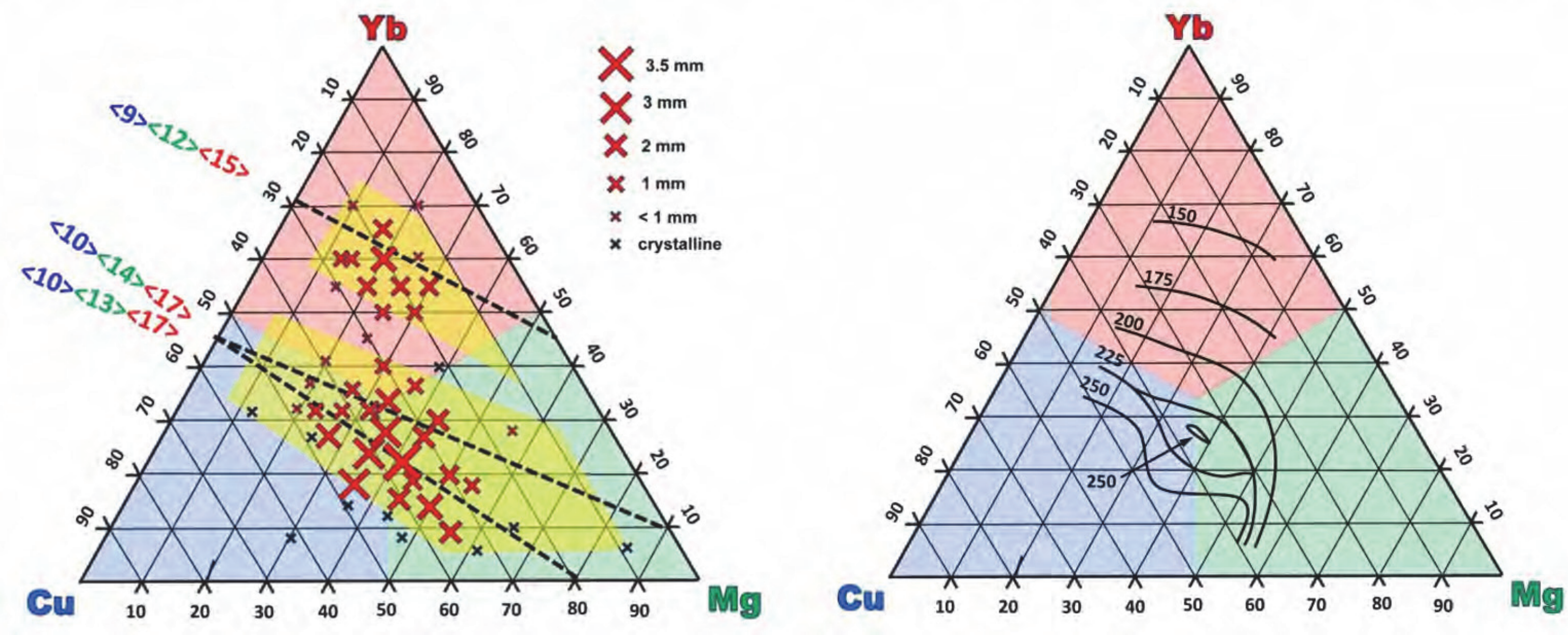